\title{
A MODEL OF A SURGING GLACIER
}

\author{
By E. BRÜCKL
}

(Institut für Geophysik, Technische Hochschule Wien, A-ı o4o Wien, Austria)

\begin{abstract}
As the cause of a surge we assume a sudden improvement of the sliding conditions at the glacier bed. This improvement has the same effect on the behaviour of the glacier as an equivalent variation of the annual balance. We are therefore able to apply Nye's (1963) theory of the advance and retreat of glaciers to our problem. A simple glacier model discussed in this theory shows as a consequence of an improvement of the sliding conditions, an additional discharge of ice, which can be separated in two phases. The first phase of strong motion yields a transport of ice from the upper to the lower part of the glacier. The ice essentially remains within the previous limits of the glacier. The sequence of motion during this phase corresponds to a surge. The second phase of motion is essentially slower. During this phase the ice accumulated in the lower part of the glacier flows beyond the previous limits, till the whole surface level is lowered.

RÉsumé. Un modèle de glacier en crue rapide. Comme cause d'une crue rapide, nous pouvons admettre l'hypothèse d'une soudaine amélioration des conditions de glissement sur le lit du glacier. Cette amélioration a les mêmes effets sur le comportement du glacier qu'une variation équivalente du bilan annuel. Nous pouvons donc appliquer à notre problème la théorie de Nye (rg63) sur l'avance et le retrait des glaciers. Un modèle simple de glacier considéré dans la théorie que l'on vient de citer, montre qu'à une amélioration des conditions de glissement répond un débit additionnel de masses de glace qui peut être séparé en deux phases. La première phase de fort mouvement produit un transport des masses de glace du haut en bas du glacier. La glace reste cependant à peu près à l'intérieur des limites antérieures du glacier. La sucession des mouvements pendant cette phase correspond à une crue. La seconde phase du mouvement est essentiellement plus lente. Pendant cette phase, la glace accumulée dans la partie basse du glacier, s'étale au-delà des limites antérieures du glacier, jusqu'à ce que le niveau superficiel du glacier soit entièrement abaissé.

Zusammenfassung. Ein Modell für einen ausbrechenden Gletscher. Als Ursache eines Gletscherausbruches wird eine plötzliche Verbesserung der Gleitbedingungen am Gletscherbett angenommen. Diese hat dieselbe Wirkung auf das Verhalten des Gletschers, wie eine äquivalente Änderung der jährlichen Massenbilanz. Dadurch ist es möglich, die Theorie der Gletscherschwankungen (Nye, 1963) auch auf das vorliegende Problem anzuwenden. Das in dieser Theorie diskutierte einfache Gletschermodell ergibt als Folge einer Verbesserung der Gleitbedingungen eine in zwei Phasen ablaufende zusätzliche Eisbewegung. Die erste, rasch ablaufende Phase bewirkt eine Umlagerung von Eismassen aus dem oberen Teil des Gletschers in den unteren. Die Eismassen bleiben aber im wesentlichen innerhalb der ursprünglichen Grenzen des Gletschers. Diese Phase entspricht dem Bewegungsablauf während eines Ausbruchs. Die zweite Phase läuft wesentlich langsamer ab. Während dieser fliessen die im unteren Gletscherteil angehäuften Eismassen über das frühere Gletscherende hinaus, so dass schliesslich die gesamte Gletscheroberfläche einsinkt.
\end{abstract}

\section{INTRODUCTION}

An exciting and still unsolved phenomenon in glaciology is the occurrence of surges. A glacier stagnant for some tens of years suddenly starts to move with exceptionally high velocity. Great masses of ice are transported from the upper to the lower part of the glacier in one or two years. As a result of this movement, the surface level in the upper part is lowered and the lower part is raised, but the ice does not move beyond the limits of the previously stagnant ice. As a result of the surge, medial moraines are deformed into loops. From this characteristic it can be deduced that a surge is a repeating phenomenon. No external cause can be found for a surge (Post, I 96o) and it seems very probable that it is caused by a variation of the sliding conditions at the glacier bed (Weertman, I962).

In this paper we try to find a theoretical model which explains the sequence of motion during a surge, assuming a sudden improvement of the sliding conditions. As a prototype the surge of Muldrow Glacier described by Post ( 1960 ) will be used.

\section{General equations}

We consider a two-dimensional model of a glacier. As in the theory of advance and retreat of glaciers, we need two equations. First the continuity equation and secondly a relation between the discharge $q(x, t)$ and the ice thickness $h(x, t)$ and its derivative $\partial h(x, t) / \partial x$. This relation can be deduced from a general flow law which implies the flow law of the ice and 
the sliding conditions at the glacier bed. As in the present problem we are concerned with changes of the sliding conditions, we have to consider $q$ as a function of the parameters $\alpha_{i}$ of the general flow law too. We make the assumption, that the mathematical form of the general flow law always remains the same.

If we regard only perturbations (suffix 1 ) from a steady state (suffix o) we may write the two equations:

$$
\begin{gathered}
\frac{\partial q_{\mathrm{I}}}{\partial x}+\frac{\partial h_{\mathrm{I}}}{\partial t}=a_{\mathrm{I}} \\
q_{\mathrm{I}}=\left(\frac{\partial q}{\partial h}\right)_{0} h_{\mathrm{I}}+\left(\frac{\partial q}{\partial(\partial h / \partial x)}\right)_{\mathrm{o}} \frac{\partial h_{\mathrm{I}}}{d x}+\sum_{i=\mathrm{I}}^{n}\left(\frac{\partial q}{\partial \alpha_{i}}\right)_{0} \alpha_{i \mathrm{I}}
\end{gathered}
$$

where $a_{\mathrm{I}}(x, t)$ is the deviation from a mean annual balance $a_{0}$. $x$ is measured positive from the upper end of the glacier along the surface and $h$ is perpendicular to the $x$-direction.

Eliminating $h_{\mathrm{I}}$ and $q_{\mathrm{r}}$ respectively we obtain from Equations (I) and (2) the equations:

$$
\begin{aligned}
& \frac{\partial q_{\mathrm{I}}}{\partial t}=-\left(\frac{\partial q}{\partial h}\right)_{0} \frac{\partial q_{\mathrm{I}}}{\partial x}-\left(\frac{\partial q}{\partial(\partial h / \partial x)}\right)_{0} \frac{\partial^{2} q_{\mathrm{1}}}{\partial x^{2}}+\sum_{i=1}^{n}\left(\frac{\partial q}{\partial \alpha_{i}}\right)_{0} \frac{\partial \alpha_{i \mathrm{I}}}{\partial t}+\left(\frac{\partial q}{\partial h}\right)_{0} a_{\mathrm{I}}+\left(\frac{\partial q}{\partial(\partial h / \partial x)}\right)_{0} \frac{\partial a_{\mathrm{I}}}{\partial x} \\
& \frac{\partial h_{\mathrm{I}}}{\partial t}=-\frac{\partial}{\partial x}\left(\frac{\partial q}{\partial h}\right)_{0} h_{\mathrm{I}}-\left[\left(\frac{\partial q}{\partial h}\right)_{0}+\frac{\partial}{\partial x}\left(\frac{\partial q}{\partial(\partial h / \partial x)}\right)_{0}\right]_{\frac{\partial h_{\mathrm{I}}}{\partial x}}-\left(\frac{\partial q}{\partial(\partial h / \partial x)}\right)_{0} \frac{\partial^{2} h_{\mathrm{I}}}{\partial x^{2}}- \\
& -\sum_{i=1}^{n} \frac{\partial}{\partial x}\left(\frac{\partial q}{\partial \alpha_{i}}\right)_{0} \alpha_{i \mathrm{I}}-\sum_{i=1}^{n}\left(\frac{\partial \alpha}{\partial \alpha_{i}}\right)_{0} \frac{\partial \alpha_{i \mathrm{I}}}{\partial x}+a_{\mathrm{I}}
\end{aligned}
$$

The third term on the right side of Equation (3) represents the influence of a change in the sliding conditions on $q_{\mathrm{I}}$. It is equivalent to a variation of the annual balance $a_{\mathrm{I}}{ }^{\prime}$ which can be found from the first-order differential equation

$$
\left(\frac{\partial q}{\partial(\partial h / \partial x)}\right)_{0} \frac{\partial a_{\mathrm{r}}{ }^{\prime}}{\partial x}+\left(\frac{\partial q}{\partial h}\right)_{0} a_{\mathrm{r}}{ }^{\prime}-\sum_{i=1}^{n}\left(\frac{\partial q}{\partial \alpha_{i}}\right)_{0} \frac{\partial \alpha_{i \mathrm{I}}}{\partial t}=0 .
$$

In the same manner we can replace the fourth term on the right side of Equation (4) by an equivalent variation of the annual balance $a_{\mathrm{I}}$ " given by

$$
a_{\mathrm{I}}^{\prime \prime}+\sum_{i=1}^{n} \frac{\partial}{\partial x}\left(\frac{\partial q}{\partial \alpha_{i}}\right)_{0} \alpha_{i \mathrm{I}}+\sum_{i=1}^{n}\left(\frac{\partial q}{\partial \alpha_{i}}\right)_{0} \frac{\partial \alpha_{i \mathrm{I}}}{\partial x}=0 .
$$

With Equations (5) and (6) we have reduced our problem to the response of glaciers to climatic changes. We are therefore able to apply the theory of advance and retreat of glaciers (Nye, ig63) with only small modifications.

\section{Special model}

For the description of the glacier flow we adopt a power law (Nye, I959).

$$
q=h U\left(\frac{\tau}{T}\right)^{n},
$$

Where $\tau$ is the shear stress at the glacier bed and as a first approximation is given by

$$
\tau=\rho g h\left(\beta-\frac{\partial h}{\partial x}\right),
$$

$\beta$ is the inclination of the glacier bed, $\rho$ the density of the ice, and $g$ the gravity acceleration. 
At any datum state of the glacier we are able to choose the coefficients $U$ and $T$ in such a manner that $q$ becomes independent of $n$. If we do this, $U$ is consequently the mean velocity of the ice and $T$ the basal shear stress at this datum state.

For $(\partial q / \partial h)_{0}$ which represents the velocity of the kinematic waves, and $[\partial q / \partial(\partial h / \partial x)]_{0}$ which is the diffusion coefficient, we adopt the same polynomials as discussed and used by Nye $\left(\right.$ I $\left._{9} 3\right)$.

$$
\begin{gathered}
\left(\frac{\partial q}{\partial h}\right)_{0}=(n+\mathrm{I}) \frac{q_{0}}{h_{0}}=\frac{x}{\sigma}\left(\mathrm{I}-\frac{x}{l}\right), \\
\left(\frac{\partial q}{\partial(\partial h / \partial x)}\right)_{0}=\frac{n \rho g h_{0} q_{\mathrm{o}}}{\tau_{\mathrm{o}} h_{0}}=-\frac{x^{2}}{\sigma}\left(\mathrm{I}-\delta-\frac{x}{l}\right),
\end{gathered}
$$

where $l(\mathbf{I}-\delta)$ is the length $L$ of the glacier and $\sigma$ is a natural time unit. For a glacier of $L \approx$ Io $\mathrm{km}$ a rough estimate gives $\sigma \approx$ ro year and $\delta \approx 0.0$. This estimate of $\sigma$ is only valid if the exponent $n$ is about 3 or 4 . If we vary $n \rightarrow n_{\mathrm{I}}$ we have to multiply $\sigma$ by the factor $(n+\mathbf{I}) /$ $\left(n_{\mathrm{I}}+\mathrm{I}\right)$.

If we choose $U$ and $T$ in Equation (7) in such a manner that $(\partial q / \partial n)_{0}=0, \Sigma\left(\partial q / \partial \alpha_{i}\right)_{0}$ reduces using Equations (7) and (9) to

$$
\left(\frac{\partial q}{\partial T}\right)_{\mathrm{o}}=-\frac{n h_{\mathrm{o}} q_{\mathrm{o}}}{T_{\mathrm{o}} h_{\mathrm{o}}}=-\frac{n h_{\mathrm{o}} x}{(n+\mathrm{I}) T_{\mathrm{o}} \sigma}\left(\mathrm{I}-\frac{x}{l}\right) \text {. }
$$

We adopt for $h_{\mathrm{o}} / T_{\mathrm{o}}$ the constant value $\left(h_{\mathrm{o}} / T_{\mathrm{o}}\right)_{x=L / 2}$. Following from Equation (8), this simplification means a uniform surface inclination of the whole glacier. Therefore $\mathcal{T}_{0}$ tends to zero for $x \rightarrow 0$ and $(\mathrm{I}-\delta) l$ in the same manner as $h_{0}$. From Equations (IO) and (I I) we see that $[\partial q / \partial(\partial h / \partial x)]_{0}$ and $(\partial q / \partial T)_{o}$ should have the same analytical form. But as we need only the approximate form of the coefficients, the difference between the adopted polynomials will not falsify the results.

\section{Solution}

After having determined the coefficients of Equation (3) we look for a solution which satisfies the following conditions: $a_{\mathrm{I}}=0$ for any time; for $t<0$ we assume a steady state with $h_{\mathrm{I}}, \partial h_{\mathrm{I}} / \partial x, \partial T_{\mathrm{I}} / \partial t=0$ and an arbitrary $n$; for the small time interval $\mathrm{o} \leqslant t<\Delta t$ we take a constant $\partial T_{\mathrm{I}} / \partial t=\mathcal{T}_{\mathrm{I}} / \Delta t$. For $t \geqslant \Delta t$ we take $\partial T_{\mathrm{I}} / \partial t=0$.

In our model $T_{0}$ tends to zero for $x \rightarrow 0$ or $(\mathrm{I}-\delta) l$. As we shall assume $T_{\mathrm{I}}$ constant and negative, this will lead to a basal shear stress in the direction of the glacier flow, which is physically meaningless. But as this discrepancy is restricted to the highest and lowest part of the glacier it can hardly affect the solution of Equation (3) for the main part of the glacier.

The variation of the annual balance equivalent to the adopted variation of the sliding conditions is found by Equation (5) to be

$$
a_{\mathrm{r}}^{\prime}=-\frac{n h_{0} T_{\mathrm{I}}}{(n+\mathrm{I}) T_{\mathrm{o}} \Delta t} .
$$

With $a_{1}$ and the coefficients given by Equations (9), (I0) and (I I), the solution of Equation (3) for the time interval $o \leqslant t<\Delta t$ is given by (Nye, I963)

$$
q_{\mathrm{I}}=-\frac{n h_{0} T_{\mathrm{I}}}{(n+\mathrm{I}) T_{0} \Delta t}\left[\{\mathrm{I}-\exp (-t / \sigma)\} x+\frac{\mathrm{I}}{\mathrm{I}-2 \delta}\{\exp (-t / \sigma)-\exp (-2 \delta t / \sigma)\} \frac{x^{2}}{l}\right] .
$$

We expand $\exp (-t / \sigma)$ and $\exp (-2 \delta t / \sigma)$ into series and, taking $\Delta t \rightarrow 0$, we find for $q_{\mathrm{r}}$ at $t=\mathrm{o}$

$$
q_{\mathrm{r}}=-\frac{n h_{\mathrm{o}} T_{\mathrm{I}} x}{(n+\mathrm{I}) \sigma T_{\mathrm{o}}}\left(\mathrm{I}-\frac{x}{l}\right) .
$$

A sudden change of $T_{0}$ to $T_{0}+T_{1}$ yields therefore a $q_{1}$ given by Equation (12). 
For $t \geqslant \Delta t$ we have to solve the homogenous differential equation (3) with the initial condition (12). The solution is

$$
q_{\mathrm{I}}=-\frac{n h_{0} T_{\mathrm{I}}}{(n+\mathrm{I}) \sigma T_{0}}\left[x\left(\mathrm{I}-\frac{x}{l}\right) \exp (-t / \sigma)+\frac{x^{2}}{l} \frac{2 \delta}{\mathrm{I}-2 \delta}(\exp (-2 \delta t / \sigma)-\exp (-t / \sigma)]\right) .
$$

The solution for $h_{\mathrm{r}}$ is found from Equations (I3) and (I):

$$
h_{\mathrm{I}}=\frac{n h_{\mathrm{o}} T_{\mathrm{I}}}{(n+\mathrm{I}) T_{\mathrm{o}}}\left[\mathrm{I}-\left(\mathrm{I}-\frac{x}{l} \frac{2}{\mathrm{I}-2 \delta}\right) \exp (-t / \sigma)-\frac{l}{x} \frac{2}{\mathrm{I}-2 \delta} \exp (-2 \delta t / \sigma)\right]
$$

\section{Discussion}

From Equation (I3) we see that a sudden change of $T_{\mathrm{o}}$ to $T_{\mathrm{o}}+T_{\mathrm{I}}\left(T_{\mathrm{I}}\right.$ negative) causes an additional discharge $q_{\mathrm{I}}$ which can be separated into two phases. The first phase, represented by the first term in Equation (13), describes a discharge which reaches its maximum in the middle of the glacier and vanishes completely at the head and nearly at the snout. The motion caused by this discharge yields a transport of ice from the upper part of the glacier to the lower part and decays from a maximum at the beginning with a time constant $\sigma$. No essential transport of ice beyond the previous limits of the glacier takes place.

The second phase of motion, represented by the second term in Equation (13), becomes important after the first has decayed. It increases quadratically toward the end of the glacier and therefore causes an advance. Its magnitude is smaller by the factor $2 \delta$, but, decaying with the time constant $\sigma / 2 \delta$, it continues correspondingly longer. $\sigma / 2 \delta$ is known as the long time constant from the theory of advance and retreat of glaciers.

We find a similar behaviour in $h_{\mathrm{r}}$. During the first phase of rapid motion the surface level lowers in the upper part of the glacier and rises in the lower part. During the second phase, decaying with the long time constant $\sigma / 2 \delta$, the surface level in the lower part drops too, till a constant decrease of ice thickness $h_{\mathrm{I}}=n h_{0} T_{\mathrm{I}} /(n+\mathrm{I}) T_{0}$ over the whole glacier is reached. The resulting diminution of the length of the glacier is of no physical significance for $\left|T_{\mathrm{I}}\right|>T_{0}$ at the extreme ends of the glacier as mentioned in the previous section.

Qualitatively the first phase of motion is very similar to a surge. To fit our model quantitatively we assume $T_{\mathrm{r}} \approx \frac{1}{4} T_{\mathrm{o}}$ to get the right magnitude of the surface level variation. $\sigma$, normally about io years, must be more than io-times smaller during a surge to yield the very fast motion observed. This corresponds to a very high value of the exponent $n$. Normally no advance is produced by a surge. The first phase of motion of our theoretical model meets this observation. The second phase, transporting ice beyond the steady-state end of the glacier, is weaker by the factor $2 \delta$ than the first phase. One could imagine that this second phase is suppressed if a consolidation of the sliding conditions takes place after the first phase of strong motion is over.

MS. received I 8 May I97I

\section{REFERENCES}

Nye, J. F. 1959. The motion of ice sheets and glaciers. Fournal of Glaciology, Vol. 3, No. 26, p. 493-507.

Nye, J. F. 1963 . On the theory of the advance and retreat of glaciers. Geophysical Fournal of the Royal Astronomical Society, Vol. 7, No. 4, p. $43 \mathrm{I}^{-} 56$.

Post, A. S. r 960 . The exceptional advances of the Muldrow, Black Rapids, and Susitna Glaciers. Journal of Geophysical Research, Vol. 65, No. I1, p. 3703-12.

Weertman, J. 1962. Catastrophic glacier advances. Union Géodésique et Géophysique Internationale. Association Internationale d'Hydrologie Scientifique. Commission des Neiges et des Glaces. Colloque d'Obergurgl, IO-9-18-9 I962, p. $3 \mathrm{I}-39$. 